\title{
Understanding and reducing the anthropogenic heat emission
}

Book or Report Section

Accepted Version

Chrysoulakis, N. and Grimmond, C. S. B. (2016)

Understanding and reducing the anthropogenic heat emission. In: Santamouris, M. and Kolokotsa, D. (eds.) Urban climate mitigation techniques. Routledge, pp. 27-40. ISBN 9780415712132 Available at https://centaur.reading.ac.uk/52736/

It is advisable to refer to the publisher's version if you intend to cite from the work. See Guidance on citing.

Publisher: Routledge

All outputs in CentAUR are protected by Intellectual Property Rights law, including copyright law. Copyright and IPR is retained by the creators or other copyright holders. Terms and conditions for use of this material are defined in the End User Agreement.

\section{www.reading.ac.uk/centaur}

\section{CentAUR}

Central Archive at the University of Reading 
Reading's research outputs online 


\title{
UNDERSTANDING AND REDUCING THE ANTHROPOGENIC HEAT EMISSION
}

\author{
Nektarios Chrysoulakis ${ }^{1}$ and C.S.B. Grimmond ${ }^{2}$
}

\begin{abstract}
${ }^{1}$ Foundation for Research and Technology - Hellas, Institute of Applied and Computational Mathematics, N. Plastira 100, Vassilika Vouton, 70013, Heraklion, Greece, T +30-2810-391762, zedd2@iacm.forth.gr ${ }^{2}$ University of Reading, Department of Meteorology, Reading UK RG6 6BB, UK T+ 44118378 6248, C.S.Grimmond@ reading.ac.uk
\end{abstract}

\section{INTRODUCTION}

Cities and the behaviour of their residents change through time. The spatial organization of urban areas, whether the footprint and height of buildings; the width, length, and layout of streets; where people live and where they work; the walkability and scale of neighbourhoods; the relative proximity of urban amenities; the type and diversity of urban green space all affect urban energy use. The global urban population is expected to increase up to 7 billion by 2050 (United Nations, 2010). Thus there are enormous opportunities to shape the built environment and for urban planning to play an important role in climate change mitigation (implementation of mitigation technologies, such as green roofs and cool materials) and adaptation (adaptation measures, such as emergency management plans) at the city level (Santamouris 2014). Mitigating climate change can be achieved better by regulating land-use change than $\mathrm{CO}_{2}$ emissions reductions alone (Stone 2009). The regionalized impacts of the anthropogenic heat emissions on climate have the effect of more directly localizing the benefits of land-based mitigation (Stone et al. 2012).

One important challenge facing the urbanization and global environmental change community is to understand the relations between urban form, energy use and carbon emissions at different spatial and temporal scales. Yet, these types of analyses are needed by urban planners, who recognize that zoning a city at the local scale affects mobility and transportation choices, energy consumption and climate. As indicated by Seto and Christensen (2013), what is missing from most existing climate action plans is a clear link between urban land-use patterns beyond the individual parcel or building scale and energy use.

Energy enters passes and leaves a city in numerous ways and physical states and forms; for example, fossil fuels, electricity, radiation and heat. Construction materials, food, water and waste also store energy. What type of energy is considered depends on perspectives and applications. For example, urban planners, economists and statisticians, tend to focus on fluxes of energy that are "usable" for day-to-day activities and the optimization of this, with concern for questions such as how to influence energy consumption by administrative means, such as guidelines or regulation for insulation of new houses, traffic reduction etc. Meteorologists, in contrast, are more interested in understanding how energy in forms such as radiation and heat influences the urban climate and how it is transported and stored in the urban fabric and atmosphere. Energy flow charts by urban planners usually omit radiation and anthropogenic heat as a heating source (Chrysoulakis et al. 2009). Urban meteorologists, in contrast, consider them in the Urban Energy Budget (UEB), taking account of the anthropogenic heat resulting from vehicular emissions, space heating and cooling of buildings, industrial processing and the metabolic heat release by people.

The focus of this chapter is the anthropogenic heat flux, its quantification and significance and opportunities to moderate its effect on the urban climate.

\section{QUANTIFYING THE ANTHROPOGENIC HEAT FLUX}

Given the three dimensional nature of the urban ecosystem, the UEB approach considers a control volume, i.e. all terms in the balance equation represent fluxes into, or out of, or the storage change of this volume (Figure 1). The surface energy balance, with units of energy ( $\mathrm{J}$, joules) per unit time ( $\mathrm{s}$, seconds) per surface area $\left(\mathrm{m}^{2}\right)$, is defined for the top of the volume as:

$$
\mathrm{Q}^{*}+\mathrm{Q}_{\mathrm{F}}=\mathrm{Q}_{\mathrm{H}}+\mathrm{Q}_{\mathrm{E}}+\Delta \mathrm{Q}_{\mathrm{S}}+\Delta \mathrm{Q}_{\mathrm{A}}+\mathrm{S} \quad\left(\mathrm{J} \mathrm{s}^{-1} \mathrm{~m}^{2}=\mathrm{W} \mathrm{m}^{-2}\right)
$$

where $Q^{*}$ is the net all-wave radiation, $Q_{F}$ is the anthropogenic heat flux, $Q_{H}$ is the turbulent sensible heat flux, $Q_{E}$ is the turbulent latent heat flux, $\Delta \mathrm{Q}_{\mathrm{S}}$ is the net change in heat storage within the volume (the volume is defined such that the flux into the ground is incorporated in $\left.\Delta \mathrm{Q}_{\mathrm{S}}\right), \Delta \mathrm{Q}_{\mathrm{A}}$ is the net advected flux $\left(\Delta \mathrm{Q}_{\mathrm{A}}=\mathrm{Q}_{\text {in }}-\mathrm{Q}_{\text {out }}\right)$ and $\mathrm{S}$ represents all the other sources and sinks (e.g. heat removed by runoff, photosynthetic heat etc.); the heat-to-wastewater flux (Iamarino et al. 2011) is also included in S. This equation is applicable for small time steps $(1 \mathrm{~h})$, or if the UEB is integrated over the course of a 24-h period, the net storage term may be assumed small and ignored.

Significant advances have been made in the simulation of the physics of urban climate processes associated with enhanced computational capacity, improved Earth Observation (EO) sensors and model developments (Arnfield 2003, Weng 2009, Grimmond et al. 2010, 2011). $\mathrm{Q}_{\mathrm{F}}$ is difficult to determine because of its strongly varying pattern and because it is very difficult to measure directly. $\mathrm{Q}_{\mathrm{F}}$ consists of both sensible and latent heat components. Their relative importance varies not only with urban land use but also by time of year. In areas where evaporative towers are used in large cooling 
systems the latent heat portion can be about $25 \%$ of total $\mathrm{Q}_{\mathrm{F}}$ in summer; for example central Tokyo (Moriwaki et al. 2008) and Osaka Prefecture (Narumi et al. 2009, 23\%).

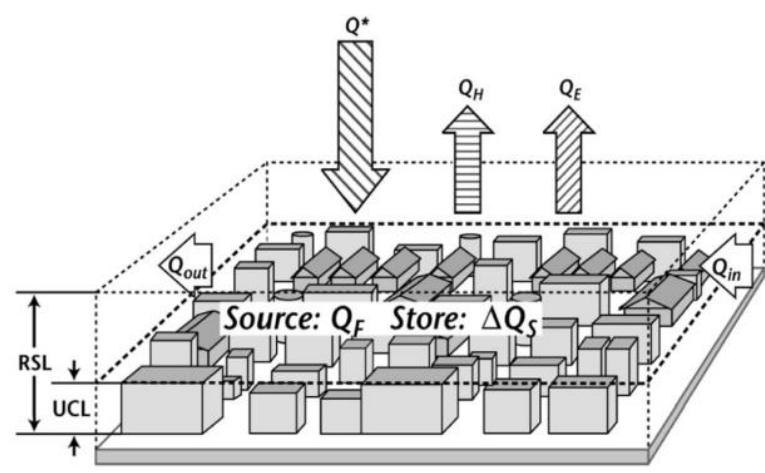

Figure 1. Conceptual illustration of the fluxes in the energy balance of an urban building-soil-air volume (source: Roberts et al. 2006). UCL is the Urban Canopy Layer and RSL is the Roughness Sub-Layer.

There are three general approaches to estimate $\mathrm{Q}_{\mathrm{F}}$ (Sailor, 2011):

- Inventories: Commonly socio-economic data are used with energy use data to the three main contributors: mobile (e.g. traffic), stationary sources (buildings) and metabolic (human) release. The fraction of traffic as a function of type and amount of gasoline, the number of vehicles, their fuel efficiency and the distance they travel commonly are used. For stationary sources, consumer-scale long term data can be divided into short term fluctuations using large scale hourly variations of electricity/gas consumption (Grimmond 1992, Sailor and Lu 2004, Moriwaki et al. 2008, Hamilton et al. 2009, Smith et al. 2009). Recently, Iamarino et al. (2012) assessed the spatial variability of $\mathrm{Q}_{\mathrm{F}}$ from buildings using highresolution resident and workplace population data. They concluded that buildings are the major source of anthropogenic heat emissions, accounting for about $80 \%$ of the nearly $150 \mathrm{TWh}$ of waste energy annually emitted across the Greater London. As discussed by Sailor (2011) such inventory approaches are limited by resolution. Typically, energy consumption data have good temporal resolution at coarse spatial scales, but poor temporal resolution at more detailed spatial resolution. In addition, assumptions have to be made about energy consumption and its relation to release and the location of the release (e.g. all to the external environment).

- Residual of the UEB: A second approach to estimate $\mathrm{Q}_{\mathrm{F}}$ is to calculate the flux as the residual of the UEB (eqn 1). This is a more physically-based method all errors of the other terms are cumulated the residual flux. This method also assumes energy balance closure for the time interval of calculation. Measurements of the other UEB terms may have systematic biases, for example, if the turbulent heat fluxes are underestimated by the measurement technique (e.g. Eddy Covariance) or insufficient sampling (e.g. to obtain measurements to determine the storage or radiative fluxes). To simplify, the problem long time periods are used, so storage term can be assumed to be negligible (Pigeon et al. 2007). Furthermore, there is the incorrect assumption that all the UEB fluxes are commonly measured at the same spatial scale. The high level of uncertainty associated with residual $\mathrm{Q}_{\mathrm{F}}$ means both the temporal and spatial resolution are coarse (of the order $10^{2}-10^{3} \mathrm{~m}$ ) and diurnal profiles cannot be resolved. Thermal remote sensing may have the potential to improve this approach (see, for example, Kato and Yamaguchi 2005, 2007, Rigo and Parlow 2007, Kato et al. 2008, Xu et al. 2008).

- Building energy models: As the release of anthropogenic heat is typically largest from the building sector, it has been the subject of many focused studies. These bottom-up studies generally involve explicit modelling of energy consumption within buildings and careful evaluation of heat emissions. Typically prototypes buildings are modelled using detailed building energy simulations. These results can then be integrated with an urban canopy meteorological model, which for completeness requires the other two components of $\mathrm{Q}_{\mathrm{F}}$ to be accounted for (transport and metabolism). The building energy sub-models explicitly account for building occupants, radiative transfer through windows, type of air-conditioning heat exchanger (air-cooled vs evaporatively cooled) and performance of airconditioning systems, in addition to the building shape, materials, etc. The use of such a detailed building energy sub-model results in more realistic estimate of anthropogenic emissions (Kikegawa et al. 2003, Sailor 2011, Bueno et al. 2012). For the most part, these building sector prototype approaches have focused on generating representative profiles of anthropogenic emissions of heat and moisture rather than broader estimates. Only recently have the models been dynamically linked with urban atmosphere models (Sailor 2011, Bueno et al. 2012). These can provide data at high spatial and temporal resolution but the contribution of transport is ignored.

A better understanding of local scale interactions between typical urban units and the atmosphere is needed for both urban planning and landscaping and climate mitigation strategies. In particular, the key characteristics governing energy exchange between the surface and atmosphere have to be identified if adequate action is to be taken to improve thermal comfort, reduce energy use, or reduce the impacts of extreme heat/cold events. Such knowledge is also critical for a better characterization of boundary layer processes and therefore for applications in the fields of air quality and pollutant dispersion. In many cases the release of this heat is also associated directly (e.g. vehicles) or indirectly (e.g. buildings) with pollutant release, whether the greenhouse gas of carbon dioxide or small particulates (e.g. $\mathrm{PM}_{10}$ ). Thus changes in energy use and heat release may also change the pollutants that are released and/or the location of their release.

\section{THE IMPORTANCE OF THE ANTHROPOGENIC HEAT FLUX}

Nearly all energy used for human purposes is dissipated as heat within the Earth's surface-atmosphere system. Thermal 
energy released from non-renewable sources is therefore a climate forcing term. Flanner (2009) estimates that averaged globally this forcing is only $+0.028 \mathrm{~W} \mathrm{~m}^{-2}$, but over the continental United States and Western Europe, it is +0.39 and $+0.68 \mathrm{~W} \mathrm{~m}^{-2}$, respectively. The anthropogenic heat flux emission is though strongly affected by climate and weather, because this determines whether heating or cooling systems are used. In the USA, between 60 and $70 \%$ of energy consumption in buildings is used for heating, air-conditioning and water heating (Heiple and Sailor, 2008). While predicting climate change and its impacts at a global scale has uncertainties, local effects of urbanization on the climate have long been documented. Recent work has documented that most large U.S. cities are warming at double the rate of the planet as a whole, a trend attributed to rapid growth in the UHI phenomenon (Stone et al. 2012). Urban warming has important implications for human comfort, health and well-being. Many examples exist of the vulnerability of urban populations, most often young children, the elderly and the poor, associated with heat waves; for example in Chicago (1995), India (1998), France, Spain and UK (2003) and Russia (2010). Future climate scenarios, which predict an increase in summertime maximum temperatures and also in the frequency and magnitude of extreme conditions, suggest greater risks for vulnerable people in the future. Warmer conditions in cities will also increase demand for air conditioning. More air conditioners generate more heat and have significant effects on the local-scale external climate, with implications for human comfort and the demand for cooling. At a larger scale, greater use of air conditioning results in more greenhouse gases through increased electricity generation. Concurrent with rising heat wave activity also is a growing incidence of heat related health effects among urban populations and more frequent failures of critical infrastructure, such as electrical power generation and transmission systems. Confronted with these trends, many urban governments have revised or developed new heat wave emergency response plans, as part of broader climate change mitigation and adaptation strategies. This has broader implications in terms of the management of energy resources to reduce $\mathrm{Q}_{\mathrm{F}}$.

$\mathrm{Q}_{\mathrm{F}}$ varies widely through the year, through the day, between countries and urban areas. Although typical values in cities range from $5-100 \mathrm{~W} \mathrm{~m}^{-2}$ (Christen and Vogt 2004, Allen et al. 2011), very high $\mathrm{Q}_{\mathrm{F}}$ values under extreme localized conditions have been reported. In a modern city core with high-rise buildings and intense traffic, $\mathrm{Q}_{\mathrm{F}}$ can exceed $100 \mathrm{~W}$ $\mathrm{m}^{-2}$; for example $\mathrm{Q}_{\mathrm{F}}$ values up to $550 \mathrm{~W} \mathrm{~m}^{-2}$ for London (Iamarino et al. 2012). Furthermore, changes in energy consumption due to changes in climate are predicted to cause a $13 \%(11 \%)$ increase in $\mathrm{Q}_{\mathrm{F}}$ on summer (winter) weekdays in Europe (Lindberg et al. 2013). The largest impact results from changes in temperature conditions, which influences building energy use. The spatial resolution used to model $\mathrm{Q}_{\mathrm{F}}$ is critical and highlights implications for scientific understanding and decision making. High resolution databases $(100 \mathrm{~m}$ x $100 \mathrm{~m})$ typically are only developed for individual cities or small areas within them (Lindberg et al. 2013). At the other extreme are the global $\left(0.5^{\circ} \mathrm{x} 0.5^{\circ}\right)$ datasets; for example Flanner (2009).

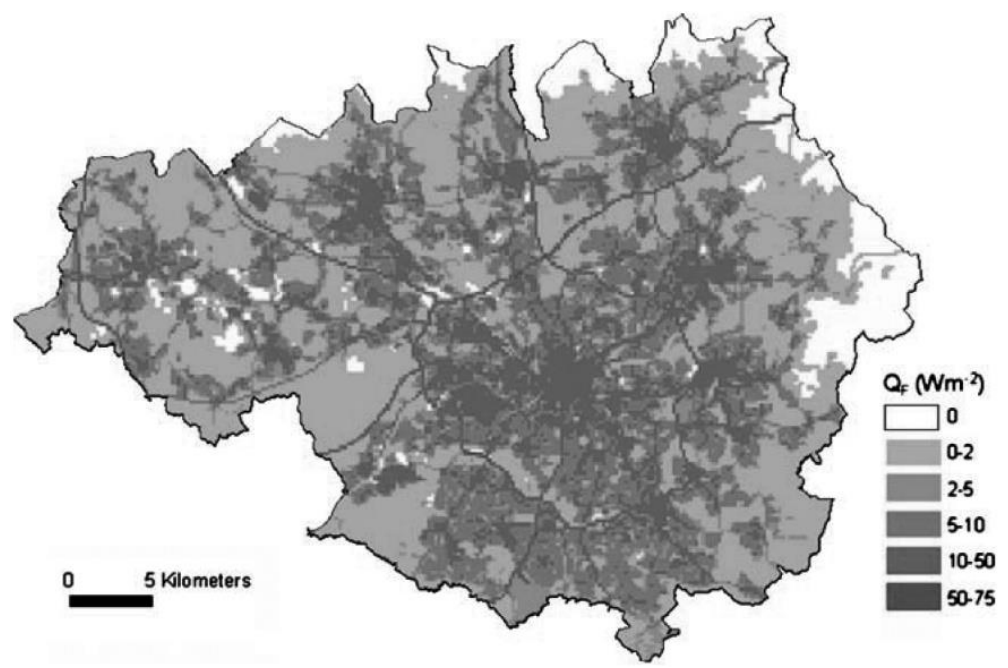

Figure 2. Daily averaged $Q_{F}\left(W^{-2}\right)$ estimates for Greater Manchester at $200 \mathrm{~m} \times 200 \mathrm{~m}$ grid, using urban morphology units (source: Smith et al. 2009).

The magnitude of $\mathrm{Q}_{\mathrm{F}}$ is highly dependent on the spatial scale at which it is estimated. In cities, peak values are associated with large buildings and busy roads. Smith et al. (2009) estimated $\mathrm{Q}_{F}$ spatiotemporal patterns for the city of Manchester at $200 \mathrm{~m} \times 200$ resolution, using a top-down approach based on urban morphology units. Their daily averaged $\mathrm{Q}_{\mathrm{F}}$ estimates (Figure 2) highlighted the potential for exposure to localized heat sources which may lead to additional thermal discomfort and overheating during the summer months; and conversely the potential for lowered energy consumption due to a decrease in heating demand in urban centres during winter. Lindberg et al. (2013) employed the Large-scale Urban Consumption of energY (LUCY) model to estimate the spatial distribution of $Q_{F}$ across Europe for the period 1995 - 2015, considering changes in temperature, population and energy use. They found that while on average $\mathrm{Q}_{\mathrm{F}}$ was small (of the order $1.9-4.6 \mathrm{~W} \mathrm{~m}^{-2}$ across all the urban areas of Europe), significant spatial variability existed (maximum $185 \mathrm{~W} \mathrm{~m}^{-2}$ ). Therefore, while still small at the individual sites, aggregated over the entire urban area of Europe $\mathrm{Q}_{\mathrm{F}}$ represents a large amount of additional energy that needs to be accounted for in considerations of urban energy exchanges, as shown in Figure 3 (Lindberg et al. 2013). 


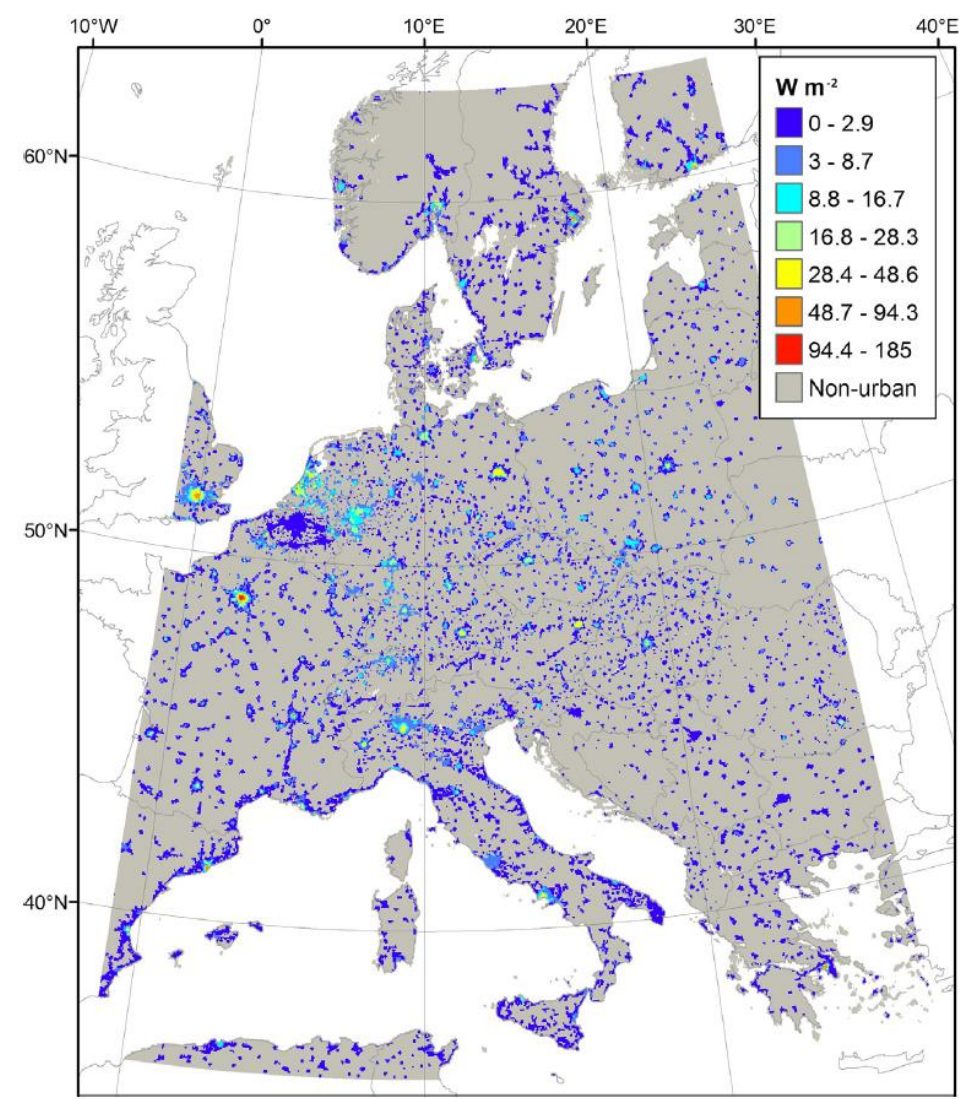

Figure 3. Daily averaged $Q_{F}\left(W m^{-2}\right)$, based on LUCY (Largescale Urban Consumption of energy) model simulations for $14^{\text {th }}$ February 2005. Population distribution is an important factor in the spatial distribution of $Q_{F}$. This is exemplified by comparing e.g., London and Paris, two similar cities based on size and population, but Paris is predicted to have a much higher peak in $Q_{F}$, because of higher population density at its city centre (source: Lindberg et al. 2013).

In terms of its temporal variability, as a general rule, the diurnal profile of total anthropogenic heating has local peaks in the early-morning and late-afternoon, corresponding to peaks in transportation and building energy use. However, in commercial and industrial areas these peaks maybe less obvious. Grimmond et al. (2010) argue that $\mathrm{Q}_{\mathrm{F}}$ may become especially significant in the UEB at key times of the day and night and specifically at transition times. As illustrated in Figure 4 (Sailor 2011), the diurnal profile also depends upon the day of the week, with total emissions on weekends and holidays significantly lower than emissions on workdays. The relative magnitude of the morning and evening peaks depends upon the underlying climate and the season. In summer, the afternoon peak becomes more pronounced as a result of air-conditioning loads that tend to peak between 15:00 and 17:00 local time. In the winter, the morning peak may become more pronounced as a result of heating demand in the building sector. Therefore, producing local scale spatially and temporally resolved $\mathrm{Q}_{\mathrm{F}}$ profiles would be of value not only for inclusion to, and the evaluation of, UEB models, but also for use by urban planners and designers to understand and better manage the future impacts of a changing climate on patterns of risk within urban populations.

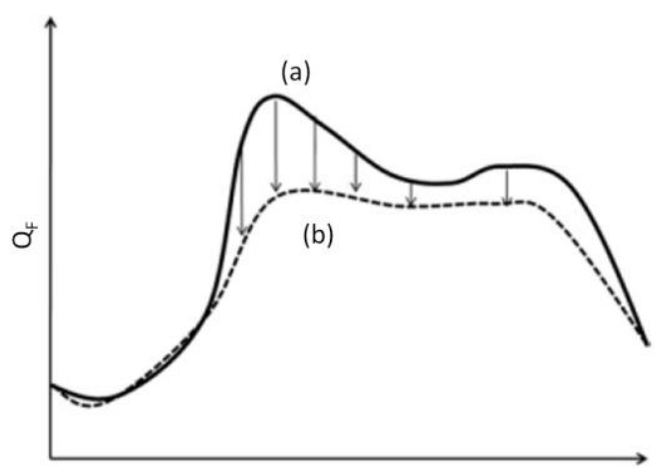

Time (h)

Figure 4. Typical shapes of diurnal profiles of anthropogenic heating for (a) work days, and (b) non-work days, illustrating local peaks in the morning and early evening hours (adapted from Sailor 2011).

The sensible anthropogenic heat emissions can lag the timing of the energy consumption and can differ substantially in magnitude. The bulk of the discharge from transportation is directly into the atmosphere and without significant time lag. As a consequence, profiles of energy generation from road fuels and atmospheric heat emissions are coincident, and the same applies to metabolic emissions from people outdoors. This is not true for the energy consumed in buildings and the metabolic emissions from people within because of the heat transfer resistance between buildings and atmosphere and the thermal inertia of buildings. Moreover, the total energy exchanged by the buildings with the atmosphere can be larger than just the anthropogenic sources in buildings, because it also includes the short-wave and long-wave radiation absorbed by buildings less the heat dissipated into the ground. Because of this, the total energy exchanged by the buildings with the atmosphere is not equivalent to the energy consumption in buildings (Iamarino et al. 2012).

Anthropogenic moisture emissions also take two forms. Heat removed from buildings can be exhausted through evaporative cooling equipment. Such heat removal is often referred to as anthropogenic latent heating, with the net effect on the urban atmosphere also being a source of moisture. The second mechanism of anthropogenic moisture emissions is the chemical reaction that occurs in the combustion of hydrocarbon fuels either in vehicle engines or combustion furnaces. This process creates anthropogenic water vapour as a result of a chemical reaction rather than phase change and is thus distinct from latent heat emissions. Usually, the term anthropogenic heat is used to refer to sensible emission of heat associated with energy consumption. The latent and chemical generation of anthropogenic moisture resulting from energy consumption in the urban environment is referred to collectively as anthropogenic moisture emissions. Sailor et al. (2007) estimated that, due to significant environmental loads, heat emission from buildings can be 50 to $100 \%$ greater than the energy consumption of the building. They also found that an important percentage of the heat emitted from buildings in the commercial core of a city such as Houston (with large buildings with evaporative cooling towers) is emitted as latent heat. 


\section{ANTHROPOGENIC HEAT FLUX and LOCAL CLIMATE ZONE}

Knowledge of $\mathrm{Q}_{\mathrm{F}}$ at the local scale is important in Local Climate Zones (LCZ) identification. Stewart and Oke (2012) formally defined LCZ as regions of uniform surface cover, structure, material, and human activity that span hundreds of metres to several kilometres in horizontal scale. LCZs simplify the broad variety of urban forms into 17 categories that are characterized by building morphology, roads, plants, soils, rock, and water. Descriptive sheets of the LCZ classes include images to enable the general urban forms to be recognized. Obviously not all urban areas fit perfectly into a LCZ and there are areas of transition. LCZ classes are local scale units, a minimum areal extent of the order of $400-1000 \mathrm{~m}$, with dimensions based on the length scales that are needed for the atmosphere to develop an internal boundary layer that is adjusted in response to surface features of the LCZ. Close to the upwind edge of the LCZ, the depth of this layer will be shallow but will develop with distance into the LCZ. This scale is common to urban planning scales. Thus LCZ system has the potential to support well-established planning projects such as Climatope Maps (Scherer et al. 1999) and Urban Climatic Maps (Ren et al. 2011). To help quantify the thermal and morphological layers of an urban climatic map, standardized metadata for urban structure, cover, fabric and metabolism can be extracted from the LCZ. Bechtel and Daneke (2012) have shown that LCZ can be determined using multiple earth observation (EO) data sources by defining five properties: the sky view factor; the fraction of impervious materials; the terrain roughness; the surface thermal admittance; and the mean annual $\mathrm{Q}_{\mathrm{F}}$. LCZs can help to identify the key processes governing the partitioning of energy at the urban surface and they also provide guidance as to what sort of $\mathrm{Q}_{\mathrm{F}}$ values should be expected for a particular area where surface characteristics are known.

\section{METHODS AND TECHNOLOGIES TO REDUCE ANTHROPOGENIC HEAT EMISSION}

Recent research has permitted the development of technological countermeasures to the impact of urban warming. Mitigation techniques aim to balance the thermal budget of cities by increasing thermal losses and decreasing the corresponding gains. As a variety of factors (e.g. surface cover, anthropogenic heat release and urban characteristics including morphology, geographic features and climatic conditions) interact with one another to generate the UHI effect, a range of measures are needed to be effective. Among the more important of the UHI mitigation techniques are those targeting the increase the albedo of the urban environment, to expand the green spaces in cities and to use the natural heat sinks in order to dissipate the excess heat strength (Santamouris 2014). Strategies for mitigation of UHI effects should therefore include measures related to: a) urban morphology and structure; b) urban materials; and c) reduction of $\mathrm{Q}_{\mathrm{F}}$.

Table 1. Categories of $Q_{F}$ reduction measures (adapted from Yamamoto 2006).

\begin{tabular}{|c|c|}
\hline Measure & Action \\
\hline Improvement in the efficiency of energy-using products & Office automation equipment and electric consumer applications \\
\hline Improvement in the efficiency of air-conditioning systems & Refrigerators and heat sources equipment \\
\hline \multirow{3}{*}{ Optimal operation of air-conditioning systems } & Proper placement of outdoor units \\
\hline & Use of cooling towers \\
\hline & Voluntary restraints on night-time operations \\
\hline \multirow{2}{*}{$\begin{array}{l}\text { Improvement in the heat insulation and thermo-shield of } \\
\text { buildings }\end{array}$} & $\begin{array}{l}\text { High-performance heat insulation materials (interior heat insulation } \\
\text { materials) }\end{array}$ \\
\hline & $\begin{array}{l}\text { High-performance heat insulation and thermo-shield materials (exterior } \\
\text { heat insulation materials) }\end{array}$ \\
\hline $\begin{array}{l}\text { Greening of buildings and adoption of water-retentive } \\
\text { materials }\end{array}$ & $\begin{array}{l}\text { Greening of buildings and adoption of water-retentive materials } \\
\text { (exterior heat insulation materials) }\end{array}$ \\
\hline $\begin{array}{l}\text { Improvement in the reflectivity of walls and roofing } \\
\text { materials }\end{array}$ & Light coloured walls and highly reflective roofing materials \\
\hline \multirow{2}{*}{ Introduction of traffic control measures } & Traffic demand management and introduction of low emission vehicles \\
\hline & Promotion of alternatives such as bicycles \\
\hline Introduction of district heating and cooling & Central control of exhaust heat from buildings (at the regional level) \\
\hline \multirow{3}{*}{ Use of untapped energy } & Use of sea, river and ground water \\
\hline & $\begin{array}{l}\text { Use of exhaust heat from urban facilities (use of exhaust heat from } \\
\text { industrial plants, subways, buildings, power plants, substations etc.) }\end{array}$ \\
\hline & $\begin{array}{l}\text { Recovery of energy from waste materials (waste power generation and } \\
\text { heat supply) }\end{array}$ \\
\hline \multirow{2}{*}{ Use of natural energy } & Photovoltaic generation \\
\hline & Use of solar heat \\
\hline
\end{tabular}

From the perspective of urban planning and design, urban planners should focus on the determination of appropriate parameters and practices, which can be modified based on technological interventions capable of reducing $\mathrm{Q}_{\mathrm{F}}$. Therefore parameters (relative to buildings and urban design) and practices (relative to traffic) can be determined in each city, and technological solutions may be proposed on their modification towards reducing the anthropogenic heat. For example, parameters relative to buildings include ventilation, shading, use of appropriate covering materials and relative position 
with regards to heat sources. The scale, at which interventions for the reduction of anthropogenic heat will be implemented, should be also defined. At local scale (neighbourhood), technologies focus on urban micro-climate and urban design. At building scale, they focus on optimization of radiation and air fluxes. At micro-scale, they focus on thermal comfort and on impacts on human health. The selection of appropriate technologies must be based on international and local practices and resources. The potential of each technology for an area, for different scales, should be evaluated. For example, at micro- or building-scale the increase of the shading by trees and reduction of surface temperature through greening rooftops and walls; and at local scale, the increase of urban density with building orientations, through the appropriate planning and design. The $\mathrm{Q}_{\mathrm{F}}$ reduction measures that are considered most effective, as summarised by Yamamoto (2006), are shown in Table 1.

A challenging aspect of assessing the impact of $Q_{F}$ on thermal comfort is the estimation of the actual location of the emissions from buildings. Some of the anthropogenic emissions occur as conduction through the building envelope. A larger fraction occurs as a result of air exchanges through the facade and through natural operation of windows and doors. The largest fraction of anthropogenic emissions from buildings comes in the form of heat and moisture removed by mechanical heating, cooling, and ventilation systems. It is thus important to know where these systems are located. As discussed by Sailor (2011), in buildings that are fewer than 10 stories tall, the heating, ventilation and air conditioning equipment may be located adjacent to the building on the ground level, on a mezzanine-level roof, or on the rooftop of the top floor. In mid- and high-rise commercial buildings, however, the emissions may be more uniformly distributed vertically on utility floors, or consolidated at the rooftop level.

Priority for implementing UHI mitigation measures has commonly been given to measures that are readily available, but there is a growing need to adopt long-term, large-scale measures. The short term, small-scale measures now being implemented are not always delivering the hoped-for results (Yamamoto 2006). For this reason the planning community need spatially disaggregated $\mathrm{Q}_{\mathrm{F}}$ data, at neighbourhood and city scales. Such information is practically impossible to derive by point in-situ fluxes measurements, while satellite remote sensing potentially is a valuable tool for estimating UEB parameters (e.g. albedo, surface cover) exploiting EO data. Currently estimation of $\mathrm{Q}_{\mathrm{F}}$ spatial patterns are a challenge but the expected near future satellite data maybe allow new methods to be developed to estimate the spatiotemporal patterns of all the UEB fluxes, including $\mathrm{Q}_{\mathrm{F}}$. These techniques would allow benchmarking of current conditions so assessment of interventions can be made to ensure that the expected benefits are obtained. EO can directly support urban planning (Chrysoulakis et al. 2013b), map surface morphology and characteristics, and evaluate the implementation of UHI mitigation technologies (Mackey et al. 2012).

Systematic effort towards of heat emissions reduction at local level is needed, as climate change mitigation policies may reduce $\mathrm{CO}_{2}$ emissions at the point of energy production, but not necessarily heat emissions associated with the user. This implies that $\mathrm{Q}_{\mathrm{F}}$ will continue to contribute to thermal discomfort and overheating (Smith et al. 2009). Understanding $\mathrm{Q}_{\mathrm{F}}$ spatiotemporal patterns is expected to lead to the development of more efficient methods and techniques for $Q_{F}$ reduction in cities, supporting the mitigation of the UHI effect and improving thermal comfort

\section{FINAL COMMENTS}

Anthropogenic heat emissions produced by human activities are one contributor to the UHI. QF sources include heat generated by the combustion process in vehicles, heat emitted by industrial processes, the conduction of heat through building walls, or emitted directly into the atmosphere by air-conditioning systems, and the metabolic heat produced by humans. The flux is strongly affected by climate and weather as this determines if heating or cooling systems are used. While $Q_{F}$ varies spatially and temporally (diurnally, seasonally and yearly), under many conditions it can exceed energy receipt from net all-wave radiation. Its diurnal profile depends upon the day of the week and has local peaks in the morning and mid-afternoon, corresponding to peaks in transportation and building energy use. QF commonly is omitted from climate models despite its local importance (Allen et al. 2011). For this reason the Earth system modeling community needs spatially disaggregated $\mathrm{Q}_{\mathrm{F}}$ data, at local and city scales. The estimation of $\mathrm{Q}_{\mathrm{F}}$ spatiotemporal patterns is therefore a major challenge, which EO may be able to contribute to.

Knowledge of $\mathrm{QF}_{\mathrm{F}}$ patterns is important for urban planning (e.g. to reduce or prevent QF hot spots), health (e.g. to estimate the impact on thermal comfort) and future proofing (e.g. to plan and implement interventions towards $\mathrm{Q}_{\mathrm{F}}$ reduction in these areas). Planning tools, such as Urban Climatic Maps and Climatope Maps, should be enriched with information on $\mathrm{Q}_{F}$ patterns. Mapping provides visualization of assessments of these phenomena to help planners, developers and policy makers make better decisions on mitigation and adaptation. The recently developed concept of LCZ (Stewart and Oke 2012) provides a means to better integrate $\mathrm{Q}_{\mathrm{F}}$ in urban climate mapping.

Knowledge of the spatial and temporal patterns of $\mathrm{Q}_{\mathrm{F}}$ are still prone to large uncertainties. Additionally a better understanding of the impact of $\mathrm{Q}_{\mathrm{F}}$ on urban climate is needed as the impact overlaps at several scales: regional and meso-scale processes, plus within the street canyon and rooftop, and within the building. Better integration of the different estimation methods (in-situ measurements, modelling and remote sensing) would permit the respective strengths to be used and potential to overcome the weaknesses of individual methods. There is potential for EO to support our understanding of the role of $\mathrm{QF}_{F}$ within the UEB but this remains underexploited. As $\mathrm{Q}_{\mathrm{F}}$ is directly linked to urban 
metabolism, it was explored within the EU FP7 project BRIDGE (Allen et al. 2011, Iamarino et al. 2012, Kotthaus and Grimmond 2012, Chrysoulakis et al. 2013a, Kotthaus and Grimmond 2013, Lindberg et al. 2013). It is clear that the reduction of $\mathrm{Q}_{\mathrm{F}}$ through interventions targeting urban metabolism optimization should be among the objectives of sustainable urban planning.

\section{REFERENCES}

Allen, L., Lindberg, F. and Grimmond C.S.B., 2011. Global to city scale urban anthropogenic heat flux: model and variability. Int. $J$. Climatol., 31, 1990 - 2005. doi: 10.1002/joc.2210.

Arnfield, A. J., 2003. Two decades of urban climate research: a review of turbulence, exchanges of energy and water, and the urban heat island. Int. J. Climatol., 23, 1 - 26.

Bechtel, B. and Daneke, C., 2012. Classification of Local Climate Zones Based on Multiple Earth Observation Data. IEEE Journal of Selected Topics in Applied Earth Observations and Remote Sensing, 5, 1191 - 1202.

Bueno, B., Pigeon, G., Norford, L. K., Zibouche, K., and Marchadier, C., 2012. Development and evaluation of a building energy model integrated in the TEB scheme. Geosci. Model Dev., 5, 433 - 448.

Christen, A., and Vogt, R., 2004. Energy and radiation balance of a central European city. International Journal of Climatology, 24, $1395-1421$

Chrysoulakis, N., Lopes, M., San José, R., Grimmond, C.S.B., Jones, M.B., Magliulo, V., Klostermann, J.E.M., Synnefa, A., Mitraka, Z., Castro, E., González, A., Vogt, R., Vesala, T., Spano, D., Pigeon, G., Freer-Smith, P., Staszewski, T., Hodges, N., Mills, G. and Cartalis, C., 2013b. Sustainable urban metabolism as a link between bio-physical sciences and urban planning: the BRIDGE project. Landscape Urban Planning, 112, 100 - 117.

Chrysoulakis, N., Esch, T., Parlow, E., Düzgünd, S. H., Tal, A., Sazova, A., Feigenwinter, C., Triantakonstantis, D., Marconcini, M. and Kavour, M., 2013b. The role of EO in sustainable urban planning and management: the GEOURBAN approach. In Proceeding of the RSCy2013: First International Conference on Remote Sensing and Geoinformation of Environment, held in Pafos, Cyprus, April 8 - 10

Chrysoulakis, N., Vogt, R., Young, D., Grimmond, C.S.B., Spano, D. and Marras, S., 2009. ICT for Urban Metabolism: The case of BRIDGE. In: Wohlgemuth, V. Page, B. and Voigt, K. (Eds): Proceedings of EnviroInfo2009: Environmental Informatics and Industrial Environmental Protection: Concepts, Methods and Tools. Hochschule für Technik und Wirtschaft Berlin, Vol. 2, pp. 183 $-193$.

Dousset, B., Gourmelon, F., Laaidi, K., Zeghnoun, A., Giraudet, E., Bretin, P., Mauri, E. and Vandentorren, S., 2011. Satellite monitoring of summer heat waves in the Paris metropolitan area. Int. J. Climatol., 31, 313- 323.

Flanner, M.G., 2009. Integrating anthropogenic heat flux with global climate models. Geophysical Research Letters, 36, L02801.

Founda, D. and Giannakopoulos, C., 2009. The exceptionally hot summer of 2007 in Athens, Greece - Atypical summer in the future climate? Global Planet. Change, 67, 227 - 236.

Grimmond, C. S. B., 1992. The suburban energy balance: Methodological considerations and results for a mid-latitude west coast city under winter and spring conditions. Int. J. Climatol., 12, 481 - 497. doi: 10.1002/joc.3370120506.

Grimmond C.S.B., Blackett, M., Best, M.J., Baik, J.J., et al., 2011. Initial Results from Phase2 of the International Urban Energy Balance Comparison Project. Int. J. Climatol., 31, 244 - 272.

Grimmond, C.S.B., Roth, M., Oke, T. R., Au, Y. C., Best, M., et al. 2010. Climate and More Sustainable Cities: Climate Information for Improved Planning and Management of Cities (Producers/Capabilities Perspective). Procedia Environmental Science, 1, 247 274.

Grimmond, C. S. B., Salmond, J. A., Oke, T. R., Offerle, B. and Lemonsu, A., 2004. Flux and turbulence measurements at a densely built-up site in Marseille: Heat, mass (water and carbon dioxide), and momentum. J. Geophys. Res.-Atmos., 109, D24101, 1 - 19.

Hamilton, I. G., Davies, M., Steadman, P., Stone, A., Ridley, I. and Evans, S., 2009. The significance of the anthropogenic heat emissions of London's buildings: a comparison against captured shortwave solar radiation. Building and Environment, 44, 807 817.

Heiple, S. and Sailor, D. J., 2008. Using building energy simulation and geospatial modeling techniques to determine high resolution building sector energy consumption profiles. Energy and Buildings, 40, 1426 - 1436.

Iamarino, M., Beevers, S. and Grimmond C.S.B., 2012. High-resolution (space, time) anthropogenic heat emissions: London 1970 2025. Int. J. Climatol., 32, 1754 - 1767. DOI: 10.1002/joc.2390.

Kato, S., Yamaguchi, Y., Liu, C. C. and Sun C. Y., 2008. Surface Heat Balance Analysis of Tainan City on March 6, 2001 Using ASTER and Formosat-2 Data. Sensors, 8, 6026 - 6044.

Kato, S. and Yamaguchi, Y., 2007. Estimation of storage heat flux in an urban area using ASTER data. Remote Sens. Environ., 110,1 17.

Kikegawa, Y., Genchi, Y., Yoshikado, H., Kondo, H., 2003. Development of a numerical simulation system toward comprehensive assessments of urban warming countermeasures including their impacts upon the urban buildings' energy-demands. Applied Energy, 76, 449 - 466.

Kato, S. and Yamaguchi, Y., 2005. Analysis of urban heat-island effect using ASTER and ETM+ Data: Separation of anthropogenic heat discharge and natural heat from sensible heat flux. Remote Sens. Environ., 99, 44 - 54

Lindberg, F., Grimmond, C.S.B., Yogeswaran, N., Kotthaus, S. and Allen, L., 2013. Impact of city changes and weather on anthropogenic heat flux in Europe 1995 - 2015. Urban Climate, 4, 1 - 15.

Masson, V., 2000. A physically-based scheme for the urban energy budget in atmospheric models. Boundary-Layer Meteorology, 94 357 - 397.

Mackey, C.W., Lee, X. and Smith, R. B., 2012. Remotely sensing the cooling effects of city scale efforts to reduce urban heat island. Building and Environment, 49, 348 - 358. 
Moriwaki, R., Kanda, M., Senoo, H., Hagishima, A. and Kinouchi, T., 2008. Anthropogenic water vapor emissions in Tokyo. Water Resour. Res., 44, W11424, doi:10.1029/2007WR006624.

Narumi, D., Kondo, A. and Shimoda, Y., 2009. Effects of anthropogenic heat release upon the urban climate in a Japanese megacity. Environmental Research, 109, 421- 431.

Offerle, B., Grimmond, C.S.B. and Fortuniak, K., 2005. Heat Storage and Anthropogenic Heat Flux in Relation to the Energy Balance of a Central European City Centre. Int. J. Climatol., 25, 1405 - 1419.

Pigeon, G., Legain, D., Durand, P. and Masson, V., 2007. Anthropogenic heat release in an old European agglomeration (Toulouse, France). Int. J. of Climat., 27, 1969 - 1981.

Ren, C., E. Y. Ng, and L. Katzschner, 2011: Urban climatic map studies: A review. International Journal of Climatology, 31, 22132233.

Rigo, G. and Parlow, E., 2007. Modelling the ground heat flux of an urban area using remote sensing data. Theor. Appl. Climatol., 90, 185 - 199.

Roberts, S.M., Oke, T.R., Grimmond, C.S.B. and Voogt, J.A., 2006. Comparison of four methods to estimate urban heat storage. J. Appl. Meteorol. Climatol., 45, 1766 - 1781.

Sailor, D. J., Brooks, A., Hart, M. and Heiple, S., 2007. A bottom-up approach for estimating latent and sensible heat emissions from anthropogenic sources. $7^{\text {th }}$ Symposium on the Urban Environment, American Meteorological Society, San Diego.

Sailor, D. J. and Lu, L., 2004. A top-down methodology for developing diurnal and seasonal anthropogenic heating profiles for urban areas. Atmos. Environ., 38, 2737 - 2748.

Sailor, D. J., 2011. A review of methods for estimating anthropogenic heat and moisture emissions in the urban environment. International Journal of Climatology, 31, 189 - 299.

Santamouris, M., 2014. Cooling the cities - A review of reflective and green roof mitigation technologies to fight heat island and improve comfort in urban environments. Solar Energy, 103, $682-703$.

Scherer, D., U. Fehrenbach, H.-D. Beha, and E. Parlow, 1999: Improved concepts and methods in analysis and evaluation of the urban climate for optimizing urban climate processes. Atmospheric Environment, 33, 4185-4193.

Seto, K. C. and Christensen, P., 2013. Remote sensing science to inform urban climate change mitigation strategies. Urban Climate, 3 , $1-6$.

Smith, C., Lindley, S. and Levermore, G., 2009. Estimating spatial and temporal patterns of urban anthropogenic heat fluxes for UK cities: the case of Manchester. Theoretical and Applied Climatology, 98, 19 - 35.

Stewart, I. D. and Oke, T. R., 2012. Local Climate Zones for Urban Temperature Studies. Bulletin of the American Meteorological Society, 93, 1879 - 1900

Stone, B., Vargo, J. and Habeeb, D., 2012. Managing climate change in cities: Will climate action plans work? Landscape Urban Planning, 107, 263 - 271.

Stone B., 2009. Land Use as Climate Change Mitigation. Environ. Sci. Technol., 43, 9052 - 9056.

United Nations, 2010. United Nations World Population Prospects: The 2010 Revision and World Urbanization Prospects: The 2011 Revision. Population Division of the Department of Economic and Social Affairs of the United Nations Secretariat. Available at: http://esa.un.org/unup/unup/ index_panel1.html.

Weng, Q., 2009. Thermal infrared remote sensing for urban climate and environmental studies: Methods, applications, and trends. ISPRS J. Photogramm., 64, 335 - 344.

Xu, W., Wooster, M.J. and Grimmond, C.S.B., 2008. Modelling of urban sensible heat flux at multiple spatial scales: A demonstration using airborne hyperspectral imagery of Shanghai and a temperature-emissivity separation approach. Remote Sens. Environ., 112 $3493-3510$

Yamamoto, Y., 2006. Measures to Mitigate Urban Heat Islands. Quarterly Review Science \& Technology Trends, 18, 65 - 83. 